\title{
Siğil Tedavisinde Sınıflandırma Algoritmalarının Performans Analizi
}

\author{
Erkan TANYILIDIZI, Murat KARABATAK, Gökçe YILDIRIM, Zeynep ÖZPOLAT \\ Fırat Üniversitesi, Teknoloji Fakültesi, Yazılım Mühendisliği, 23119 Elazığ, Türkiye \\ gokce.yildirim1426@gmail.com
}

(Geliş/Received: 15.04.2018; Kabul/Accepted: 10.09.2018)

\begin{abstract}
Özet
Siğiller, deri üzerinde HPV virüsünün sebep olduğu bir rahatsızlıktır. Belli bir süre sonra kendiliğinden geçmesine rağmen, görüntüsünün kötü olması ve günlük yaşamı olumsuz etkilemesinden dolayı hastalar genellikle tedavi olmayı tercih etmektedirler. Siğil tedavisinde belirli bir yöntem olmadığından, uzmanlar tedavi yöntemi seçiminde siğil türü ve hastanın fizyolojik özelliklerini dikkate almaktadırlar. Bu çalışmada, birçok türü bulunan siğillerden, plantar ve common siğiller için tedavi yöntemlerinin seçimi üzerinde durulmaktadır. Bu siğil türlerinin tedavisinde, İmmünoterapi ve Kriyoterapi yaygın olarak kullanılan yöntemlerdendir. Kriyoterapi, uygulaması kolay ve etkili bir tedavi yöntemi olup, İmmünoterapi ise son zamanlarda yaygınlaşan ve siğil tedavisinde yüksek oranda başarı elde edilen bir yöntemdir. Bu makalede amaç, tedavi seçiminde uzmanlara yardımcı olmak ve hastalara uygun tedavi yönteminin belirlenmesi için, veri madenciliği algoritmalarını uygun bir șekilde kullanmaktır. Kriyoterapi ve İmmünoterapi veri setlerinde yapılan sınıflandırma algoritmalarının başarımları karşılaştırılmıştır.
\end{abstract}

Anahtar Kelimeler: Siğiller, Kriyoterapi, İmmünoterapi, Veri Madenciliği

\section{Performance Analysis of Classification Algorithms in Wart Treatment}

\begin{abstract}
The warts are a disturbance that is caused by HPV viruses on the skin. Patients often prefer to be treated, although the view is self-inflicted after a certain period of time, because the appearance is bad and adversely affects daily life. As there is no specific method in the treatment of warts, specialists take into consideration the type of wart and the physiological characteristics of the patient in choosing a treatment method. In this study, selection of the treatment methods for plantar and common warts which have numerous types are warts. Immunotherapy and cryotherapy are commonly used methods in the treatment of these warts. Cryotherapy is an easy and effective treatment method and Immunotherapy is a method that has become widespread recently and achieved high success in wart treatment. The purpose of this article is to help experts in treatment selection and to use data mining algorithms appropriately to determine the appropriate treatment method for the disease. The performances of classification algorithms in cryotherapy and immunotherapy data sets were compared.
\end{abstract}

Keywords: Warts, Cryothreapy, Immunotherapy, Data Mining

\section{Giris}

Bilim dünyasında meydana gelen bir gelișme, doğrudan ya da dolaylı olarak farklı birçok disiplini etkilemektedir. Gün geçtikçe büyüyen ve karmaşıklaşan veri yığınlarından, uzmanların işine yarayacak olan bilginin elde edilmesi için veri madenciliği yöntemleri geliştirilmektedir. Veri madenciliği, disiplinler arası bir alan olduğu için buradaki gelişmeler, diğer alanlara da etki etmektedir. Bunlardan birisi de tıp alanıdır. Hastalardan elde edilen verilere, uzmanların görüşleri eklenerek veri tabanları oluşturulur. $\mathrm{Bu}$ veri tabanlarına, gerekli işlem basamakları uygulanarak bu alandaki gelişmelere katk1 sağlanabilir.

Siğiller, çoğunlukla, el ve ayaklarda meydana gelen ve insan popillama virüsünün (HPV) sebep olduğu bir rahatsızlıktır [1]. Deri ve mukoza zarlarında meydana gelmektedir. Her insanda ortaya çıkabilecek bu hastalığın farklı türleri mevcuttur. Siğillerin tedavisinde; topikal yakıcı asit, Kriyoterapi, elektrokoter, ameliyatla çıkarılması, lazerle çıkarılması, bleomisinin 
intralezyonel enjeksiyonu, Candida albicans (C. albicans), saflaștırılmıș protein türevleri (PPD) ve kabakulak, kızamık, kızamıkçı (MMR) antijenleri gibi çeşitli tedavi yöntemleri kullanılır [2]. Bu kadar çeşitli tedavi türü olmasına rağmen her insana tüm siğil türleri için uygulanacak ortak bir tedavi yöntemi bulunmamaktadır.

Siğil tedavisi yöntemleri arasında, plantar ve common siğillerinin tedavisi için sıklıkla Kriyoterapi ve İmmünoterapi yöntemleri tercih edilmektedir [3]. Kriyoterapi tedavisi, Misırlılar ve Hipokrat zamanından beri yaygın kullanılan basit ve etkili bir yöntemdir. Buz tedavisi olarak da bilinen bu yöntemde, kullanılan gaz, bir probun içerisinden geçirilerek probun ucu soğutulur. Soğuk prob, yara üzerine uygulanarak yaranın içinde ve dışında bulunan saf su dondurulur ve oradaki hücrelerin ölmesi sağlanır. 3 veya 4 seanstan sonra, yaralarda \%50-70 arasında bir iyileşme görülmektedir [4]. Ancak, bu yöntem uygulanırken çeşitli yan etkiler oluşabilmektedir. Aynı zamanda tedavi süreci uzun sürmekte ve ağrilı olabilmektedir.

Uzmanlar, Kriyoterapinin bazı olumsuz yönlerini giderebilecek alternatif bir tedavi arayışlarına girmişlerdir. İmmünoterapi ise yeni bir yöntem olarak karşımıza çıkmaktadır. İmmünoterapi, bağışıklığın temelden etkilendiği durumlarda, bağışıklık sistemini tedavi etmeyi amaçlamaktadır [5]. Siğil tedavisi için uygulanan İmmünoterapi yönteminde, çeşitli hastalıkların antijenleri siğil üzerine sürülerek bu bölgenin tedavi edilmesi amaçlanır.

$\mathrm{Bu}$ iki yöntemi karşılaştıran, literatürdeki bazı çalışmalar incelenmiştir. Khozeimeh ve ark. siğil tedavisinin seçiminde, ilk kez veri madenciliği algoritmalarını kullanmışlardır. Tedavi seçiminde önemli olan özellikler, her iki tedavi türü için de tespit edilmiştir. Bu özellikler arasındaki ilişkinin tespit edilebilmesi için apriori algoritması kullanılmıștır. Apriori algoritması uygulandığında, destek ve güven değerleri dikkate alınarak İmmünoterapi grubu için 3, Kriyoterapi grubu için 7 anlamlı kural oluşturulmuştur. Apriori algoritması ile elde edilen kurallar, uzmanların belirlediği üyelik fonksiyonlarına göre bulanık kurallara dönüştürülmüștür. Daha sonra bu kurallara ANFIS ile optimizasyon işlemi uygulanarak elde edilen sonuçlar iyileştirilmiştir [6].
Gerçekleștirilen bir başka çalışmada, dirençli siğillerin tedavisinde, kabakulak ve Candida deri testi antijenlerinin etkili olduğu gösterilmiștir. Çocuklarda görülen dirençli siğillerin tedavisi için, bir veya daha fazla siğili olan 47 pediatrik hastaya kabakulak veya Candida deri testi antijeni enjekte edilmiştir. Tedavi edilen 22 hastanın (\%47) tam olarak iyileştiği gözlemlenmiştir [7].

Özellikle common siğil tipine sahip hastalarda, İmmünoterapi MMR antijenlerinin etkinliği üzerinde de çalıșmalar yapılmaktadır. $[8,9]$. Nofal ve ark. tarafından gerçekleștirilen bu çalışmanın amacı, common siğile sahip olan hastaların tedavisinde intralezyonel kabakulak, kızamık ve kızamıkçık (MMR) aşısının etkinliğini ve güvenilirliğini değerlendirmektir. Çalışmada, bir ya da daha fazla dirençli veya dirençsiz common siğile sahip 135 hasta kullanılmaktadır. $\mathrm{Bu}$ hastalar rastgele iki gruba ayrılmaktadır. 85 kişiden oluşan birinci gruba MMR aşıları uygulanmıştır. 50 kişilik ikinci gruba ise kontrol grubu olarak tuz uygulanmıştır. Tedavi sonucunda iki grup arasında anlamlı bir fark tespit edilmektedir. MMR ile tedavi edilen grupta, dirençli ve çoklu siğile sahip hastalar üzerinde sırasıly $\% 80$ ve $\% 84.6$ başarı elde edilmiştir. MMR aşısı ile intra-immüler immünoterapi, common siğiller, özellikle de çoklu siğili olan hastalar için ümit verici, etkili ve güvenli bir tedavi olduğu sonucuna varılmaktadır [8].

Bir başka çalışmada, en az bir tane siğili bulunan 115 hasta üzerinde kabakulak ve candida antijenlerinin etkisi test edilmiştir. Kriyoterapi ile tedavi edilemeyen siğiller için kabakulak veya candida antijeni siğile enjekte edilerek tedavi edilebildiği gözlemlenmektedir [10].

Molluscum contagiosum ve siğilleri olan 217 çocuk hasta üzerinde, Candida antijeni ile immünoterapi tedavisi uygulanmıştır. Yapılan 1 yıllık gözlemler sonucunda, Candida antijenin siğil tedavisinde etkili ve güvenli bir yöntem olduğu düşülmektedir [11].

Bir diğer çalışmada amaç, viral siğillerin tedavisinde plaseboya kiyasla intradermal ve intralezyonel Candida antijeninin etkinliğini belirlemektir. 30 kişiden oluşan iki grup üzerinde yapılan deneysel çalışmaların sonuçları gözlemlenmiştir [12].

Daha önce de belirtildiği gibi, siğil tedavisi yöntemleri hastanın özellikleri ve siğil türüne 
göre değişmektedir. Hangi tür tedavinin uygun olduğunu tespit etmek, hem zaman hem de maliyet açısından büyük kayıplara sebep olmaktadır. Uzmanlara bu konuda yardımeı olmak amaciyla, veri madenciliği yöntemlerinden yararlanılabilir.

$\mathrm{Bu}$ çalışma ile, hasta özelliklerine göre Kriyoterapi ve İmmünoterapi yöntemlerinden hangisinin daha uygun olduğunu tahmin etmek amaçlanmaktadır. $\mathrm{Bu}$ amaç doğrultusunda, İmmünoterapi ve Kriyoterapi veri setlerine sınıflandırma algoritmaları uygulanmıştır. Başarımı yüksek olan algoritmalar tedavi sürecine yardımcı olmak amacıyla uzmanların hizmetine sunulmaktadir.

\section{Materyal ve Metot}

Veri madenciliği son zamanlarda gelişen ve üzerinde hala çalışılan bir alandır. Veri madenciliğinin ası amacı, veri yığınlarını kullanarak temel modellerden birini oluşturmaktır. $\mathrm{Bu}$ model üzerinden, veriler arasındaki ilişkiyi ortaya çıkarmak ve veri yığınında olmayan farklı bir verinin yorumlanmasını sağlamaktır. Veri madenciliği 3 temel modelden oluşmaktadır [13].

- Siniflandirma ve Regresyon

- Kümeleme

- Birliktelik Kuralıdır.

\subsection{Sinıflandırma}

Bir veri seti üzerinde tanımlanan sınıflara verilerin uygun bir şekilde dağıtılması işlemine sinıflandırma denir. Sinıflandırma algoritmaları ise, eğitim verilerini kullanarak sinıfların özelliklerini öğrenmede ve test verisi olarak gelen bilginin hangi sınıfa ait olduğunu tahmin etmede kullanılan algoritmalardır [14].

Sinıflandırma algortimalarından lieratürde en yaygın kullanılanlar Naive Bayes, Yapay Sinir Ağları (YSA), Destek Vektör Makinaları (SVM), K - En Yakın Komşu (IBK), KStar, C4.5 (J48) ve Random Forest algoritmalarıdır. $\mathrm{Bu}$ algoritmalar;

- J48 algoritmasi; temel olarak C4.5 algoritmalarına dayanır. C4.5 algoritmasının Weka'ya uyarlanmış hali J48 algoritmasıdır.
$\mathrm{Bu}$ algoritmanın amacı karar ağacını optimize etmektir. [15-19].

- Random Forest; birçok karar ağacı kullanarak sınıflandırma başarımını yükseltmeyi amaçlayan bir algoritmadır. Tek tek elde edilen ağaçlar bütünleştirilerek karar ormanlar1 elde edilir [20].

- Naive Bayes; temel olarak Bayes teoremine dayanmaktadır. Olasilıksal hesaplamalarla verilerin kategorilerini belirleyen algoritmadır. Naive Bayes algoritmasında önemli olan nokta bilginin nas1l sinıflandırıldığıdır $[21,22]$.

- YSA; insan beyninden esinlenerek ortaya çıkmış bir algoritmadır. Esas olarak, biyolojik sinir ağlarını taklit edeler. Veri setiyle yapılan eğitim sonucunda öğrendiği sistemle, ağa farklı girişler uygulandığında nasıl tepkiler vereceğine karar verir. Bu sistem algoritma ile bulunabilir, elle yapılandırılabilir ya da her ikisini de kullanabilir. [23 -25].

- SVM; örüntü tanıma ve sinıflandırma problemlerinin çözümü için uygulanan bir algoritmadır. Çok terimli kernel kullanarak destek vektör sınıflandırıcıyı eğitir. Bütün nitelikleri önceden tanımlanmış olan verilerle normalize eder [26]

- IBK; Çapraz doğrulama kullanarak, bilinmeyen bir örneğin dahil olduğu sınıfı belirlemek için, bu örneğe en yakın olan $\mathrm{k}$ örneklemi bulan algoritmadır. Mesafeleri ağırlıklandırabilme özelliğine de sahiptir [27, 28].

- K-Star; benzerlik fonksiyonlariyla belirlenebilen örnek tabanlı bir algoritmadır. $\mathrm{K}$-star algoritması, eğitim sinıfına ait olan örneklere dayanarak aynı verilerle test sınıfinı da olușturur. Mesafe hesaplamasını, entropi tabanlı yaparak diğer örnek tabanlı öğrenenlerden ayrilır [29]

\subsection{Karışıklık matrisi}

Karışıklık Matrisi, sınıflandırma işlemi sonucunda elde edilen değerlerin sunumu için yaygin olarak kullanılan bir tekniktir. Sınıflandırma başarımının net bir şekilde değerlendirilebilmesi için doğruluk, duyarlılık ve özgünlük değerlerinin hesaplanması gerekmektedir [15]. Bu değerler karmaşıklık 
matrisinden elde edilmektedir. Tablo 1'de karmaşıklık matrisinin yapısı verilmektedir.

Tablo 1. Karışıklık matrisi

\begin{tabular}{|c|c|c|c|}
\hline \multicolumn{4}{|c|}{ Öngörülen Sınıf } \\
\hline \multirow{3}{*}{ 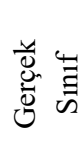 } & & EVET & HAYIR \\
\hline & EVET & TP & $\mathrm{FN}$ \\
\hline & HAYIR & FP & $\mathrm{TN}$ \\
\hline
\end{tabular}

Tablo 1'de satırlar gerçek sınıfi, sütunlar ise tahmin edilen sınıf değerlerini göstermektedir. Bu değerler aşağıda verilen formüllerde yerine yazılarak hesaplanır ve oluşturulan modelin geçerliliği incelenir.

Yöntemin geçerliliğinin belirlenmesinde kullanılan ölçütlerden biri doğruluk oranıdır. Test veri setindeki tüm veriler içerisinde, ne kadarının doğru sınıfta tahmin edildiğini ifade etmektedir.

Doğruluk $=\frac{\mathrm{TP}+\mathrm{TN}}{\mathrm{TP}+\mathrm{TN}+\mathrm{FP}+\mathrm{FN}}$

Bir diğer ölçüt ise duyarlılıktır. Duyarlılık toplam pozitif örnek sayısı içerisindeki doğru sınıflandırılmış pozitif değerleri göstermektedir.

Duyarlılık $=\frac{\mathrm{TP}}{\mathrm{TP}+\mathrm{FN}}$

Özgünlük ise gerçekten yanlış olanlar arasında, yanlış olarak tahmin edilenlerin sayısını vermektedir.

Özgünlü $k=\frac{\mathrm{TN}}{\mathrm{TN}+\mathrm{FP}}$

Veri setinin, eğitim ve test verisi olarak hangi oranlarda bölüneceğinin belirlenmesi, sınıflandırma başarımını etkilemektedir. Varolan veri seti, belirli bir oranda bölünerek veya veri setinde olmayan veriler ile ayrica test edilerek doğruluk belirlenebilir.

\section{Uygulama}

$\mathrm{Bu}$ çalışmanın temel amacı, siğil tedavisi uygulanırken hangi yöntemin hasta üzerinde etkili olduğunu tahmin etmektir. Gerçekleştirilen çalışmada, Kriyoterapi ve İmmünoterapi veri setlerine Weka'da temel siniflandirma algoritmaları uygulanmaktadır. Her bir sınıflandırma için, test seçeneklerinden 10-kat çapraz doğrulama metodu seçilmiștir. Tedavi yöntemlerinin tahmininde başarımı en yüksek olan algoritmalar kullanılmıştır.

\subsection{Veri seti}

$\mathrm{Bu}$ çalışmada, Khozeimeh ve ark. tarafindan oluşturulan veri setleri kullanılmıştır. $\mathrm{Bu}$ veri setleri, Ocak 2013'ten Şubat 2015'e kadar Meşhed'deki Ghaem Hastanesinin dermatoloji kliniğine siğil tedavisi için gelen 180 hastadan toplanan veriler ile oluşturulmuştur [6]. Veri setleri, dermatoloji kliniğine başvuran plantar ve common siğilli hastaların bilgilerinden oluşmaktadır. Bunlar en sık görülen siğil tiplerinden iki tanesidir. Hastaneye ilk gelen hasta birinci gruba, ikinci gelen hasta ikinci gruba gönderilmiştir. Her grupta toplam 90 kişi olana kadar hastalar rastgele bir şekilde gruplandırılmışıır. Birinci gruptaki hastalara Candida antijeni yöntemiyle İmmünoterapi tedavisi uygulanmıştır. İkinci grup ise, sıv1 nitrojen kullanılarak Kriyoterapi ile tedavi edilmiștir.

Sınıflandırma işlemine geçmeden önce, hastaların hangi özelliklerinin tedavi seçiminde daha etkili olduğunu tespit etmek amaciyla, özellik seçimi uygulanmaktadır. Özellik seçimi için bilgi kazancı metodunu kullanmışlardır. Bilgi kazancı metodunda, elde edilen özelliğin kazanç değeri ne kadar yüksek ise sinıflandırma görevinde de o kadar iyi bir aday özelliktir [30]. Bilgi kazancının hesaplanabilmesi için öncelikle entropi değeri hesaplanmalıdır. Daha sonra bu entropi değeri kullanılarak kazanç ölçütleri hesaplanır [31]. Özellikler, kazancı en yüksek olandan başlanarak sıralanır.

Bilgi kazanc1 metodu ile, İmmünoterapi tedavisi uygulanan 90 hasta ve bu hastalara ait 8 özellik, Kriyoterapi tedavisi için ise 90 hasta ve 7 özellik bulunmuştur. Seçilen özellikler, alanında uzman hekimlerin görüşleri de dikkate alınarak belirlenmiştir. Bu özellikler Tablo 2 ve 3 'te etkili olma sıralarına göre verilmektedir ve bu özelliklerin her biri için belirlenen sinırlar gösterilmektedir. 
Tablo 2. Kriyoterapi veri setlerinde bulunan özellikler ve değer aralıkları

\begin{tabular}{l|l}
\multicolumn{1}{c}{ KRIYYTERAPİ } & \multicolumn{1}{c}{ DEĞER ARALIKLARI } \\
\hline Tedavi öncesi geçen süre (ay) & $0-12$ \\
Yaş & $15-67$ \\
Siğil tipi & $1-$ Common (54), \\
& $2-$ Plantar (9), \\
& $3-$ Her İkiside (27) \\
Siğilin yüzey alanı $\left(\mathrm{mm}^{2}\right)$ & $4-750$ \\
Cinsiyet & 47 Erkek \\
Siğil sayısı & 43 Kadın \\
& $1-12$
\end{tabular}

Tablo 3. Kriyoterapi veri setlerinde bulunan özellikler ve değer aralıkları

\begin{tabular}{|c|c|}
\hline İMMÜNOTERAPİ & DEĞER ARALIKLARI \\
\hline davi öncesi geçen süre (ay) & $0-12$ \\
\hline $\begin{array}{l}\text { aşlangıç sertleşme çap1 } \\
\text { sti(mm) }\end{array}$ & $5-70$ \\
\hline aș & $15-56$ \\
\hline ğil tipi & $\begin{array}{l}1 \text { - Common (47), } \\
2 \text { - Plantar (22), } \\
3 \text { - Her İkiside (21) }\end{array}$ \\
\hline ğilin yüzey alanı $\left(\mathrm{mm}^{2}\right)$ & $6-900$ \\
\hline insiyet & $\begin{array}{l}41 \text { Erkek } \\
49 \text { Kadın } \\
1-19\end{array}$ \\
\hline
\end{tabular}

Her iki veri seti için de, sınıflandırma sonucu "tedavi yanıtı" sinifi altında, olumlu ise 1, olumsuz ise 0 șeklindedir. Kriyoterapi veri seti için tedaviye olumlu yanıt verenlerin sayısı 48 , olumsuz yanit verenlerin sayis1 42'dir. İmmünoterapi veri seti için ise 71 olumlu, 19 olumsuz yanıt bulunmaktadır.

\subsection{Deneysel sonuçlar}

Siğil tedavisinde, her hasta için uygulanabilecek belirli bir tedavi yöntemi bulunmamaktadır. Tedavi yönteminin belirlenebilmesi için, hastanın çeşitli fizyolojik özellikleri bilinmelidir. $\mathrm{Bu}$ özellikler incelendikten sonra, hangi yöntemin etkili olabileceği uzmanlar tarafindan belirlenmektedir. Kriyoterapi ve İmmünoterapi uygulanması için gerekli hasta özellikleri, birbirine oldukça yakındır. Çalışmanın amacı, bu algoritmalar yardımıyla hasta özelliklerini analiz ederek, hangi tedavi yönteminin daha uygun olduğunu belirlemektir. $\mathrm{Bu}$ amaç doğrultusunda, veri madenciliği yöntemlerinden yararlanılmıştır.

Gerçekleștirilen çalıșmada, literatürde bulunan farklı sinıflandırma algoritmaları veri setlerine uygulanmış ve performansları incelenmiştir. Hangi algoritmanın daha anlamlı sonuç verdiğini belirlemek için doğruluk, duyarlılık ve özgünlük değerleri hesaplanıștır. Tablo 4'de, Kriyoterapi veri seti için uygulanan sınıflandırma algoritmalarının başarım kriterleri verilmektedir

Tablo 4. Kriyoterapi veri seti için sınıflandırma başarımı

\begin{tabular}{|l|c|c|c|}
\hline Kriyoterapi & Doğruluk & Duyarlılık & Özgünlük \\
\hline Naive Bayes & 83,33 & 0,76 & 0,90 \\
\hline Yapay Sinir Ağları (YSA) & 87,77 & 0,91 & 0,85 \\
\hline Destek Vektör Makinesi (SVM) & 87,77 & 0,91 & 0,85 \\
\hline K - En Yakın Komşu (IBK) & 90,00 & 0,91 & 0,90 \\
\hline KStar & 96,66 & 0,98 & 0,96 \\
\hline C 4.5 (j48) & 93,33 & 0,98 & 0,90 \\
\hline RandomForest & 93,33 & 0,98 & 0,90 \\
\hline Bulanık Tabanlı Kural-Apriori [6] & 80,00 & 0,87 & 0,77 \\
\hline
\end{tabular}

Tablo 4'den elde edilen sonuçlar incelendiğinde, $\mathrm{K}$ - Star algoritmas1, Kriyoterapi için seçim yapilırken en iyi sonuç veren algoritmadır. Naive Bayes algoritması ise bu veri seti için diğer algoritmalar ile kıyaslandığında daha kötü bir sonuç verdiği görülmektedir. Aynı veri seti üzerinde [6]'de gerçekleştirilen bulanık mantık tabanlı kuralların başarım ölçütleri de 
tabloda verilmektedir. K-Star algoritmasının, sınıflandırmada daha başarılı olduğu görülmektedir. K-Star algoritmasına ait karışıklık matrisi Tablo 5'de verilmektedir.

Tablo 5. K-Star algoritmasına ait karışıklık matrisi

\begin{tabular}{|c|c|c|c|}
\hline \multicolumn{4}{|c|}{ Öngörülen Sınıf } \\
\hline \multirow{2}{*}{ 总 } & & Negatif & Pozitif \\
\cline { 2 - 4 } & Negatif=0 & 41 & 1 \\
\cline { 2 - 4 } & Pozitif=1 & 2 & 46 \\
\hline
\end{tabular}

Tablo 6'de ise, İmmünoterapi veri seti için elde edilen başarım sonuçları gösterilmektedir. Her bir sinıflandırma algoritması için doğruluk, duyarlılık ve özgünlük değerleri hesaplanmıştır.

İmmünoterapi veri seti incelendiğinde, tedaviye yanit veren ve vermeyen hastalar arasında homojen bir dağılım olmadığı gözlemlenmiştir. Bu veri setinde, Kriyoterapi veri setine göre bütün kriterlerin başarım oranında düşüş olduğu görülmektedir.

Tablo 6. İmmünoterapi veri seti için sınıflandırma başarımı

\begin{tabular}{|l|c|c|c|}
\hline İmmünoterapi & Doğruluk & Duyarlılık & Özgünlük \\
\hline Naive Bayes & 76,66 & 0,21 & 0,92 \\
\hline Yapay Sinir Ağları (YSA) & 81,11 & 0,42 & 0,92 \\
\hline Destek Vektör Makinesi (SVM) & 78,88 & 0,00 & 1,00 \\
\hline K - En Yakın Komşu (IBK) & 70,00 & 0,21 & 0,83 \\
\hline KStar & 74,44 & 0,32 & 0,86 \\
\hline C 4.5 (j48) & 82,22 & 0,47 & 0,92 \\
\hline RandomForest & 85,55 & 0,47 & 0,96 \\
\hline Bulanık Tabanlı Kural-Apriori [6] & 83,33 & 0,87 & 0,71 \\
\hline
\end{tabular}

Tablo 6 incelendiğinde, Destek Vektör Makinesi kullanılarak yapilan siniflandırma sonuçlarında, duyarlılık değeri sıfır olarak hesaplandığından, İmmünoterapi veri setini Destek Vektör Makineleri ile sinıflandırmanın uygun olmadığı görülmektedir. Bu veri seti için en başarılı sınıflandırma, Random Forest algoritmasina aittir.

Bulanık tabanlı kurallara göre Random Forest algoritmasının doğruluk ve özgünlük oranları daha yüksek olmasına rağmen, bulanık tabanlı algoritmanın duyarlı1ığının daha yüksek olduğu görülmektedir. Tablo 7'de, Random Forest algoritmasına ait karışıklık matrisi gösterilmektedir.

Tablo 7. Random Forest algoritmasına ait karışıklık matrisi

\begin{tabular}{|c|c|c|c|}
\hline \multicolumn{4}{|c|}{ Öngörülen Sınıf } \\
\hline \multirow{3}{*}{$\begin{array}{l}\text { 总 } \\
\text { 递 }\end{array}$} & & Negatif & Pozitif \\
\hline & Negatif $=0$ & 9 & 10 \\
\hline & Pozitif $=1$ & 3 & 68 \\
\hline
\end{tabular}

\section{Sonuç}

Siğiller, virüslerin sebep olduğu bir hastalık türüdür. Günümüzde tüm siğil türleri için uygulanabilecek bir yöntem bulunmamaktadır. Tedavi yönteminin tercihinde, veri madenciliği algoritmalarından faydalanılmıştır.

$\mathrm{Bu}$ çalışamada, veri madenciliği algortimaları yardımıyla hastanın özellikleri analiz edilerek, hangi tedavi yönteminin daha uygun olduğunu belirlenmektir. Her iki tedavinin uygulanması için gerekli olan, hastanın fizyolojik özellikleri belirlenmektedir. Kullanılan tedavi yöntemleri için, sınıflandırma algoritmalarının sonuçları analiz edilmiştir. En yüksek başarıma sahip olan K-Star ve Random Forest algoritmaları üzerinden sonuçlar değerlendirilmiştir.

Sınıflandırmada başarılı olan algortimalar incelendiğinde hangi tedavinin daha uygun olduğuna karar verilebilmektedir. Yapılan çalışmada, kriyoterapi ile tedavi edilen hastalarda, uygulanan tedavinin uygun olup olmamasina yönelik en iyi tahmin başarımını \%96,66 ile $\mathrm{K}$ - 
Star algoritmas1 elde edilmiştir. İmmünoterapiyle tedavinin, başarılı olup olmayacağını ise en iyi ortaya koyan algoritma \%85,55 başarım ile Random Forest algoritmasidir. Deneysel çalışmalar göstermektedir ki bu algoritmalar, siğil tedavisinde hangi yöntemin tercih edilebileceği konusunda uzmanlara yardımcı olabilir.

\section{Kaynaklar}

1. Rowson, K.E., Mahy, B.W. (1967). Human papova 1967; 31: 110-131.

(wart) virus. Bacteriol Rev

2. Gibbs, S., Altman, D. G., Harvey, I., Sterling, J., \& Stark, R. (2002). Local treatments for cutaneous warts: systematic review, Bmj, 325: 1-8.

3. Khozeimeh, F., Azad, F.J., Oskouei, Y.M., Jafari, M., Tehranian, S., Alizadehsani, R., Layegh, P., (2017). Intralesional immunotherapy compared to cryotherapy in the treatment of warts, International Journal of Dermatology 56: 474 478.

4. Godley, M. J., Bradbeer, C. S., Gellan, M., \& Thin, R. N. (1987). Cryotherapy compared with trichloroacetic acid in treating genital warts, Sexually Transmitted Infections, 63(6): 390-392.

5. https://www.tavsiyeediyorum.com/makale_1171 0.htm, Erişim Tarihi: 08.08.2018.

6. Khozeimeh, F., Alizadehsani, R., Roshanzamir, M., Khosravi, A., Layegh, P., Nahavandi, S., (2017). An expert system for selecting wart treatment method, Computers in Biology and Medicine 81: 167-175

7. Clifton, M.M., Johnson, S.M., Roberson, P.K., Kincannon, J., Horn, T.D., (2003). İmmunotherapy for recalcitrant warts in children using intralesional mumps or candida antigens, Pediatr. Dermatol. 20: 268-271.

8. Nofal, A., Nofal, E., (2010). Intralesional immunotherapy of common warts: successful treatment with mumps, measles and rubella vaccine, J. Eur. Acad. Dermatol. Venereol. 24: 1166-1170.

9. Horn, T.D., Johnson, S.M., Helm, R.M., Roberson, P.K., (2005). Intralesional immunotherapy of warts with mumps, Candida, and Trichophyton skin test antigens: a singleblinded, randomized, and controlled trial, Arch. Dermatol. 141: 589-594.

10. Johnson, S. M., Roberson, P. K., \& Horn, T. D. (2001). Intralesional injection of mumps or Candida skin test antigens: a novel immunotherapy for warts. Archives of dermatology, 137(4):451-455.
11. Maronn, M., Salm, C., Lyon, V., Galbraith, S., (2008). One-year experience with candida antigen immunotherapy for warts and molluscum, Pediatr. Dermatol. 25: 189-192.

12. Khurshid, K., Pal, S.S., (2009). Role of candida antigen in treatment of viral warts: a placebocontrolled study, J. Pak. Assoc. Dermatol. 19: $146-150$

13. Özkan, Y., (2008), Veri Madenciliği Yöntemleri, Papatya Yayıncılık, İstanbul

14. http://bilgisayarkavramlari.sadievrenseker.com/2 013/03/31/siniflandirma-classification/, Erişim Tarihi: 07.08.2018.

15. Coşkun, C., \& Baykal, A. (2011). Veri Madenciliğinde Sınıflandırma Algoritmalarının Bir Örnek Üzerinde Karşılaștırılması. XIII. Akademik Bilişim Konferansı Bildirileri, 51-58.

16. Patil, T. R., \& Sherekar, S. S. (2013). Performance analysis of Naive Bayes and J48 classification algorithm for data classification. International journal of computer science and applications, 6(2): 256-261.

17. Wei, C. P., \& Chiu, I. T. (2002). Turning telecommunications call details to churn prediction: a data mining approach. Expert systems with applications, 23(2): 103-112.

18. Quinlan, J. R. (1986). Induction of decision trees. Machine learning, 1(1): 81-106.

19. https://medium.com/@Emreyz/y\%C3\%B6ntemle r-4-1-c4-5-algoritmas\%C4\%B1-7382de92584e, Erişim Tarihi: 30.07.2018.

20. https://www.slideshare.net/SezerFidanc/randomforest-algoritmas, Erişim Tarihi: 01.08.2018.

21. Bayes Ağları (Bayes Network), http://bilgisayarkavramlari.sadievrenseker.com/ 2008/12/21/bayes-aglari-bayesian-network/, Erişim Tarihi: 03.08.2018.

22. https://kodedu.com/2014/05/naive-bayessiniflandirma-algoritmasi/, Erişim Tarihi: 25.07.2018.

23. Data Mining Software in Java, www.cs.waikato.ac.nz/ ml/weka/, Erişim Tarihi: 24.07.2018.

24. Kıyan, T., Yıldırım, T., (2003). Eğiticili Ve Eğiticisiz Nöral Algoritmalar Kullanarak Göğüs Kanseri Teşhisi, Elektrik -Elektronik-Bilgisayar Mühendisliği 10. Ulusal Kongresi, İstanbul, Türkiye, 453-456.

25. http://www.derinogrenme.com/2017/03/04/yapay -sinir-aglari/, Erişim Tarihi: 29.07.2018.

26. Ardıl, E., (2009). Esnek Hesaplama Yaklaşımı İle Yazılım Hata Kestirimi, Yüksek Lisans Tezi, Trakya Üniversitesi, Fen Bilimleri Enstitüsü, 86s.

27. Aha, D. W., Kibler, D., \& Albert, M. K. (1991). Instance-based learning algorithms. Machine learning, 6(1): 37-66. 
28. Özekes, S . (2003). Veri Madenciliği Modelleri ve Uygulama Alanları, İstanbul Ticaret Üniversitesi Fen Bilimleri Dergisi, 2 (3): 65-82.

29. Cleary, J. G., \& Trigg, L. E. (1995). K*: An instance-based learner using an entropic distance measure. In Machine Learning Proceedings , 108114
30. Alizadehsani, R., Habibi, J., Hosseini, M.J., Mashayekhi, H., Boghrati, R., Ghandeharioun, A., Bahadorian, B., Sani, Z.A., (2013). A data mining approach for diagnosis of coronary artery disease, Comput, Methods Prog. Biomed, 111: 52-61.

31. https://www.ce.yildiz.edu.tr/personal/.../Veri+Ma denciliği-SınıflamaKumeleme.ppt, Erişim Tarihi: 30.07.2018. 